$\Phi=5$

\title{
Pattern of interaction and relationships between family members
}

\author{
Manar Alazzam ${ }^{1}$, Mohammed Albashtawy ${ }^{1}$, Maen Aljezawi ${ }^{1}$, Abdul-Monim Batiha ${ }^{2 *}$, \\ Mazen Freij ${ }^{3}$, Barakat Khasawneh ${ }^{4}$, Fadwa Alhalaiqa ${ }^{2}$ \\ ${ }^{1}$ Faculty of Nursing, Al al-Bayt University \\ ${ }^{2}$ Faculty of Nursing, Philadelphia University \\ ${ }^{3}$ Faculty of Medicine, University of Jordan \\ ${ }^{4}$ Dental department, Princess Basma Teaching Hospital \\ *Corresponding author E-mail: abatiha@gmail.com
}

\begin{abstract}
Studying a family as a unit to describe the relationships in will allow the researcher to investigate the family as the primary unit and as a whole, which means that the family, the individuals as family members and their relationship is in the foreground. The data derived using this approach comes from the family unit functioning as a whole and does not reflect the individual members' contributions "solely" or in a combined way. Such an approach allows for more global understanding of the issues surrounding family relationships as health and social data can be collected from different aspects and dimensions within the family as a unit and it will add more significant data. Even though studying a family as a unit eliminates the non-independence issue it does raise concerns about ignoring many potentially important details of intra-family relationships. In conclusion, the premise of studying the family as a unit (family as the unit of analysis) is that the researcher can gain greater insight into families in general and a family's relationships in particular.
\end{abstract}

Keywords: Family Members; Community Health; Pattern Of Interact; Family Relationships.

It is reported in much of the literature that the family is greater than or "different from" the sum of its parts (Gilliss \& Davis, 1992; Zarnaghash, 2011). A description of the family as a unit has evolved over the time to emphasize the fact that it "is a complex unit with unique attributes of its own but containing component parts that are significant as individual units, both independently and collectively" (Gilliss \& Davis, 1992; Rose, 2012). Such a description emphasizes the importance of the family to its individuals and vice versa, giving more understanding about the family as a unit when researchers also study its parts. Furthermore, the family has been identified as an entity that as a unit acts and reacts to events (Rose, 2012). It was believed that studying the family as a unit means studying the family separately from its parts. There is a conceptual confusion in the literature regarding what constitutes the family as a unit and the unit of analysis at the same time (Bussing et al., 2015; Gilliss \& Davis, 1992) and this makes it difficult to develop the study design, adding further complexity to studying the family as a unit.

Studying a family as a unit to describe the relationships in will allow the researcher to investigate the family as the primary unit and as a whole, which means that the family, the individuals as family members and their relationship is in the foreground (Bussing et al., 2015; Kendall, Leo, Perrin, \& Hatton, 2005). The data derived using this approach comes from the family unit functioning as a whole and does not reflect the individual members' contributions "solely" or in a combined way (Rose, 2012). Such an approach allows for more global understanding of the issues surrounding family relationships as data can be collected from different aspects and dimensions within the family as a unit (Knafl, Darney, Gallo, \& Angst, 2010) and it will add more significant data. Even though studying a family as a unit eliminates the nonindependence issue it does raise concerns about ignoring many potentially important details of intra-family relationships (Kendall et al., 2005).

Studying a family as a unit focuses on studying the family individuals, their pattern of interaction and the relationships between them as a unit. Such an approach requires that the researcher acquires multiple family members as participants in the study, to gain greater insight into the phenomena of the family studied. Thus, such studies call for using the appropriate conceptual framework (Rose, 2012).

Advantages of using theoretical frameworks that focus on the family as a unit include viewing the family as a whole more than each member separately (Gilliss \& Davis, 1992; Neabel, Fothergill-Bourbonnais, \& Dunning, 2000). Such models allow the researcher to view the "dynamic individual" the "dynamic unit" and their interrelatedness, as the family components are dependent on each other. Furthermore, studying the family as a unit requires integrating more than one theoretical model to conceptualize the problem at a family level (ALBashtawy, 2015; ALBashtawy, 2014; ALBashtawy et al., 2015; Taylor \& de Vocht, 2011; Theule, Wiener, Tannock, \& Jenkins, 2013), and this indeed contributes to the complexities of pursuing a family as a unit. In addition, the availability of theoretical models that can be used at the family level is scarce, since the majority of existing models were developed with the individual in mind and not the family as a unit. Systems theory is one example of the models that have been used to study the family as a unit, derived from the general systems theory; the assumption of this theory is that a family is greater than and different from the sum of its parts, and individuals in the fami- 
ly are interdependent and interactive (Kaakinen, Coehlo, Steele, Tabacco \& Hanson, 2014). Once again, using such a model is not easy when it comes to studying the family as a unit because of the multi-level approach required in this model.

Research design in studying family as a unit is another huge issue, and both quantitative and qualitative research can be used. For example, using exploratory design can help in gathering more information about the family as a unit since the purpose of such design is to generate ideas, or understandings about family that are not well understood (Kaakinen et al., 2014), in this instance the "family unit" is used. In other words, it can be used to find out the important issues and variables in such a system. This design is more flexible than other research designs. On the other hand, conducting such research on a family level may impose several constraints, such as who will constitute the sample, how a representative sample is recruited, how the researcher collects the appropriate information using the appropriate tools, data analysis issues, and so forth (AlAzzam et al., 2016; AlAzzam \& ALBashtawy, 2016; ALBashtawy, 2012; ALBashtawy, 2017; Michielsen et al., 2013; Theule et al., 2013; Thomas, Skelley, Wheeler, \& Gonzalez, 2016).

The same limitations apply to other quantitative research designs: descriptive, correlation, experimental and longitudinal. The advantages of using these methods are decided by the fact that the researcher will be able to capture the richness of conceptualization and insight that characterizes the family as a unit. However, the cost of implementing such studies would be vast, as would the amount of data that would be derived from the sample (Zarnaghash, 2011).

The qualitative approach allows the researcher to discover and uncover the "perceptions", "meanings", "understandings", "multiple realities" and "psychosocial context" in families (Kaakinen et al., 2014; Rose, 2012; Thomas et al., 2016), which will help in generating more information about studying the family as a unit, and will provide insights into the issues and concerns surrounding the approach. The outputs of such design can then be used as a base for implementing quantitative designs to further investigate the phenomena of the family as a unit (Zarnaghash, 2011).

Researchers have to consider the effect of the research setting on the study, especially when the participants' home is the place of collecting data. Some of the issues concern the privacy of the participants; it is essential to maintain the privacy of the family unit members, especially children and care receivers and those who are vulnerable to other family members in terms of "power differential". This issue may arise as a result of the need sometimes to interview more than one family member at the same time and in the same place in front of each other (Alhalaiqa et al. 2015; Batiha \& ALBashtawy, 2013; Bashayreh et al., 2013; Chen \& Boore, 2009; Kaakinen et al., 2014; Khamaiseh \& ALBashtawy, 2013; Khamaiseh \& ALBashtawy, 2015; Qaddumi et al, 2016; Rohany, Ahmad, Rozainee \& Shahrazad, 2011; Saifan, et al, 2015; Tawabeh et al., 2015).

To study the relations in families, the researcher may conduct studies that use self-reporting or observation techniques or both to collect the required data ( AlAzzam, Sulaiman \& ALBashtawy, 2017; ALBashtawy et al., 2016; Ayoub et al., 2016; Gilliss \& Davis, 1992; Theule et al., 2013). Self-reporting provides rich data, but the main threat of this approach is bias from the informant and the "coder"; the informant's responses provide their own reality about the family, and bias from the coder as this is who interprets and reinterprets the informant's data through a "personal perceptual screen" (Michielsen et al., 2013; Theule et al., 2013). In terms of observation, this can be an expensive technique depending on the location and the way of observation.

The final aspect of studying the family as a unit is the data analysis. As already mentioned, to gain information about the relationships in the family unit, data have to come from multiple family members as a unit. However, analyzing and interpreting this variety of information in a conceptual, meaningful way in order to summarize the combined results is difficult (Cohen, Thompson, Yates, Zimmerman, \& Pullen, 2015; Friedlander, Kivlighan Jr, \&
Shaffer, 2012; Gray, 2003; Lamont et al., 2013). There is no consensus on how to analyze this data (Friedlander et al., 2012).

in conclusion, the premise of studying the family as a unit (family as the unit of analysis) is that the researcher can gain greater insight into families in general and a family's relationships in particular. However, several issues may arise in this process, including concern over bias if not all the members of a given family are willing to participate; such bias may come from both the informants and the coder. Furthermore, "recruitment", "retention", and coordination of the family as a unit can be difficult from a practical standpoint. in addition, scoring problems occur when using multiple family members as a source of data because of the fact that most instruments are designed for individual use. all these issues may affect the reliability and validity of the study, which may have an impact on the generalizability and the significance of the study results.

\section{References}

[1] AlAzzam, M. \& ALBashtawy, M. (2016). Famly approaches to dealing with a child's ADHD. Journal of Family Health, 26 (5), 29 33.

[2] AlAzzam, M., ALBashtawy, M., Al-Kloub, M., Eshah, N., Baker, O., ALOmari,O.\& Alkhawaldeh., A. (2016). Advantages and disadvantages of studying the family as a context approach when dealing with a school-aged child diagnosed with ADHD. Iranian journal of public health 45 (10), 1369-1370.

[3] AlAzzam, M., Sulaiman, M. \& ALBashtawy, M. (2017). School nurses, role in helping children with attention-deficit hyperactivity disorders. NASN School Nurse, 32 (1), 36 - 38 https://doi.org/10.1177/1942602X16648192.

[4] ALBashtawy, M. (2012). Oral health patterns among schoolchildren in Mafraq Governorate, Jordan. Journal of School Nursing 28(2), 124-129. https://doi.org/10.1177/1059840511427405.

[5] ALBashtawy, M. (2014). Knowledge, attitudes and practices of Parents /Guardians regarding pediculosis in the Umm el-Jmal District of Jordan. Journal of Research in Nursing. 19(5) 390-399.

[6] ALBashtawy, M. (2015). Exploring the reasons why school students eat or skip breakfast, Nursing children and young people 27(6):16-22. https://doi.org/10.7748/ncyp.27.6.16.e622.

[7] ALBashtawy, M. (2017). Assessment of hand-washing habits among school students aged 6-18 years in Jordan. British Journal of School Nursing, 12(1), 30-36. https://doi.org/10.12968/bjsn.2017.12.1.30.

[8] ALBashtawy, M., Batiha, A., Tawalbeh, L., Tubaishat, A. \& AlAzzam, M. (2015). Self -medication among school students. Journal of School Nursing, 31(2), 110-116. https://doi.org/10.1177/1059840514554837.

[9] ALBashtawy, M., Gharaibeh, H., Alhalaiqa, F., Batiha, AM., Freij., M. , Saifan , A, Al- alwamreh, K., Hamadneh. SH., Al-Kloub, M. \& Khamaiseh, A. (2016). The Health Belief Model's Impacts on the Use of Complementary and Alternative Medicine by Parents or Guardians of Children with Cancer. Iran J Public Health, 45(5), 708-709.

[10] Alhalaiqa, F., Masa'Deh, R., Batiha, A. M., \& Deane, K. (2015) Validity of Arabic version of beliefs about medication questionnaire. Clinical nursing research, 24(5), 539-555. https://doi.org/10.1177/1054773814545383.

[11] Ayoub,G., Batiha, AM., Al-Zaru, I., Alhalaiqa, F., Farahat, H ., \& AlBashtawy, M2016).).The relationship between sleep disturbance in late pregnancy and labor outcomes. International Journal of Health, 4 (1), 12-16. https://doi.org/10.14419/ijh.v4i1.5559.

[12] Bashayreh,I. Saifan,A., Batiha, A-M. \& Aburuz,M.(2013). Family Presence during CPR in Adult Critical Care Settings: Hearing the Voice of Jordanian Health Professionals. Life Science Journal 10(4):1738-1748

[13] Batiha, A-M\& ALBashtawy, M. (2013). Knowledge of Philadelphia University Students Regarding Blood Donation. Transfusion Medicine, 23(3), 195-198. https://doi.org/10.1111/tme.12027.

[14] Bussing, R., Meyer, J., Zima, B. T., Mason, D. M., Gary, F. A., \& Garvan, C. W. (2015). Childhood ADHD symptoms: association with parental social networks and mental health service use during adolescence. International journal of environmental research and

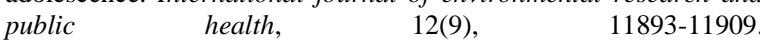
https://doi.org/10.3390/ijerph120911893.

[15] Chen, H. Y., \& Boore, J. R. (2009). Living with a relative who has a spinal cord injury: A grounded theory approach. Journal of clini- 
cal nursing, 18(2), 174-182. https://doi.org/10.1111/j.13652702.2008.02355.x.

[16] Cohen, M. Z., Thompson, C. B., Yates, B., Zimmerman, L., \& Pullen, C. H. (2015). Implementing common data elements across studies to advance research. Nursing outlook, 63(2), 181-188. https://doi.org/10.1016/j.outlook.2014.11.006.

[17] Friedlander, M. L., Kivlighan Jr, D. M., \& Shaffer, K. S. (2012). Exploring actor-partner interdependence in family therapy: Whose view (parent or adolescent) best predicts treatment progress? Journal of counseling psychology, 59(1), 168-182. https://doi.org/10.1037/a0024199.

[18] Gilliss, C., \& Davis, L. (1992). Family nursing research: precepts from paragons and peccadilloes. Journal of advanced nursing, 17(1), 28-33. https://doi.org/10.1111/j.1365-2648.1992.tb01815.x.

[19] Gray, B. A. (2003). Analysis of multiple respondent data. Journal of Family Nursing, 9(3), 345-352. https://doi.org/10.1177/1074840703255450.

[20] Kaakinen, J. R., Coehlo, D. P., Steele, R., Tabacco, A., \& Hanson, S. M. H. (2014). Family health care nursing: Theory, practice, and research: FA Davis.

[21] Kendall, J., Leo, M. C., Perrin, N., \& Hatton, D. (2005). Modeling ADHD child and family relationships. Western Journal of Nursing Research, 27(4) https://doi.org/10.1177/0193945905275513.

[22] Khamaiseh, A. \& ALBashtawy, M. (2013). Oral health knowledge, attitudes, and practices among secondary school students. British Journal of School Nursing, 8 (4), 194-2001. https://doi.org/10.12968/bjsn.2013.8.4.194.

[23] Khamaiseh, A. \& ALBashtawy, M. (2015). Prevalence of Obesity and Physical Inactivity Behaviors among Nursing Students in $\mathrm{Mu}$ tah University, Jordan. World Journal of Medical Sciences, 12 (2): 95-102.

[24] Knafl, K. A., Darney, B. G., Gallo, A. M., \& Angst, D. B. (2010). Parental perceptions of the outcome and meaning of normalization. Research in nursing \& health, 33(2), 87-98. https://doi.org/10.1002/nur.20367.

[25] Lamont, J. H., Devore, C. D., Allison, M., Ancona, R., Barnett, S. E., Gunther, R., Wheeler, L. S. (2013). Out-of-school suspension and expulsion. Pediatrics, 131(3), 1000-1007. https://doi.org/10.1542/peds.2012-3932.

[26] Michielsen, M., Comijs, H. C., Semeijn, E. J., Beekman, A. T., Deeg, D. J., \& Kooij, J. S. (2013). The comorbidity of anxiety and depressive symptoms in older adults with attentiondeficit/hyperactivity disorder: A longitudinal study. Journal of af$\begin{array}{lll}\text { fective } & \text { disorders, } & \text { 220-227. }\end{array}$ https://doi.org/10.1016/j.jad.2012.11.063.

[27] Neabel, B., Fothergill-Bourbonnais, F., \& Dunning, J. (2000). Family assessment tools: A review of the literature from 1978-1997. Heart \& Lung: The Journal of Acute and Critical Care, 29(3), 196209. https://doi.org/10.1067/mhl.2000.106938.

[28] Qaddumi, J., Holm,M., Alkhawaldeh, A., ALBashtawy, M., AL Omari,O., Batiha,AM., Alhalaiqa,F., Suliman,M., Aljohani, K. \& Da'she, A. (2016). Prevalence of Hypertension and Prehypertension among Secondary School Students. International Journal of Advanced Nursing Studies, 5 (2) 240-245. https://doi.org/10.14419/ijans.v5i2.6878.

[29] Rohany, N., Ahmad, Z. Z., Rozainee, K., \& Shahrazad, W. W. (2011). Family functioning, self-esteem, self-concept and cognitive distortion among juvenile delinquents. The Social Sciences, 6(2), 155-163. https://doi.org/10.3923/sscience.2011.155.163.

[30] Rose, D. K. (2012). Rural Family Caregiving for Children with Complex Chronic Conditions: A Grounded Theory Study. UNIVERSITY OF MINNESOTA.

[31] Saifan,A., Bashayreh,I., Batiha, A-M. \& Aburuz,M. (2015),Patientand Family Caregiver-Related Barriers to Effective Cancer Pain Control. Pain management nursing, 16(3):400-410. https://doi.org/10.1016/j.pmn.2014.09.007.

[32] Tawalbeh, L., Tubaishat, A. , Batiha, A. , AlAzzam, M. \& ALBashtawy, M. (2015).The Relationship between Social Support and Adherence to Healthy Lifestyle among Patients with Coronary Artery Disease in the North of Jordan. Clinical Nursing Research, 24(2):121-38, https://doi.org/10.1177/1054773813501194.

[33] Taylor, B., \& de Vocht, H. (2011). Interviewing separately or as couples? Considerations of authenticity of method. Qualitative Health Research, 21(11), $1576-1587$. https://doi.org/10.1177/1049732311415288.

[34] Theule, J., Wiener, J., Tannock, R., \& Jenkins, J. M. (2013). Parenting stress in families of children with ADHD a meta-analysis. Journal of Emotional and Behavioral Disorders, 21(1), 3-17. https://doi.org/10.1177/1063426610387433.
[35] Thomas, A., Skelley, J., Wheeler, J., \& Gonzalez, E. (2016). Transitions of Care Operations at a Family Medicine Clinic: Patient Follow Up and Financial Outcome Analysis. INNOVATIONS in pharmacy, 7(1), 6 .

[36] Zarnaghash, M. (2011). The Relationship between the Desired Disciplinary Behavior and Family Functioning Locus of Control and Self Esteem among High School Students in Cities of Tehran Province. Procedia-Social and Behavioral Sciences, 30(1), 2438-2448. 